\title{
The Development of New Molecules Having Antiemetic Activity Using Molecular Modeling
}

\author{
${ }^{1}$ Khalil Errahmane Kanouni* and ${ }^{2}$ Yacine Benguerba \\ ${ }^{1}$ Department of Process Engineering, Faculty of Technology, Laboratory of Chemical Process Engineering, \\ Sétif-1-University, 19000 Sétif, Algeria \\ ${ }^{2}$ Centre de Recherche en Biotechnologie (CRBt), Constantine, Algeria
}

\author{
Article history \\ Received: 25-12-2019 \\ Revised: 11-02-2020 \\ Accepted: 24-02-2020 \\ Corresponding Author: \\ Khalil Errahmane Kanouni \\ Department of Process \\ Engineering, Faculty of \\ Technology, Laboratory of \\ Chemical Process Engineering, \\ Sétif-1- University, 19000 \\ Sétif, Algeria \\ Email: khalilkanouni@hotmail.com
}

\begin{abstract}
The solubility of a drug in water or in the blood represents the most desired parameter in medicine. Our aim is to obtain molecules with properties more effective than those of metoclopramide. In this work, two molecules with high solubility are constructed. Metoclopramide (a benzamide derivative) is a dopamine receptor antagonist used as an antiemetic drug. Its solubility in water is $200 \mathrm{mg} / \mathrm{L}$ at $25^{\circ} \mathrm{C}$. In this work, we will develop two other molecules that have the same therapeutic activity of metoclopramide with a higher solubility in water, therefore in the blood, without affecting the other properties. The two molecules developed by molecular modeling with a chemical modification of the $\mathrm{OH}$ group of metoclopramide have a high solubility: approximately 3 times and 8 times that of metoclopramide. For the other physicochemical properties, there is a great similarity between the molecules. Thus, the two proposed molecules will have antiemetic activity, the second molecule will be more favorable because of its higher solubility and the number of HBA and HBD.
\end{abstract}

Keywords: Solubility, Drug, Metoclopramide, Antiemetic, Molecular Modeling

\section{Introduction}

Computers have become indispensable tools in modern pharmaceutical chemistry (Lewars, 2019). The role of the latter has become very essential, both in the discovery of new drugs and the development of them (Cui, 2011). Rapid advances in software and hardware have meant that most of the operations that could be done by experienced computer scientists can now be performed by pharmaco-chemists, with computers commonly used in laboratories, provided they possess the elementary notions of quantum mechanics and other equations that relate to molecules (Stellmach, 2009).

Molecular modeling (Zhang et al., 2019a) is an application of theoretical and computational methods to solve problems involving molecular structure and chemical reactivity. Molecular modeling is the investigation of molecular structures, (Baran, 2019) using computational computer chemistry (Jolfaei et al., 2020) and graphical visualization techniques (Zhu et al., 2018) to give a plausible three-dimensional representation in defined circumstances and to determinate the physicochemical properties.

Molecular modeling involves the use of theoretical calculation methods (Bošnjaković-Pavlović et al., 2019) (molecular mechanics, molecular dynamics, ab-initio or semi-empirical quantum mechanics (Wormald and Hawari, 2017), ...) to determine the graphical representation of the geometry or the configuration of the molecule atoms (Barabaś et al., 2019) and to evaluate the physicochemical properties of the studied molecule (Lecerf et al., 2019). Molecular modeling associated with an infographic representation of stereochemistry makes it possible to interpret physico-chemical phenomena (Rasmussen et al., 2018), to suggest new experiments and thus to analyze results in a more critical way than the experiments conventionally used (Zeng et al., 2018), but these two purely theoretical approaches or experimental are complementary.

An antiemetic is a drug that can relieve preventatively or curative vomiting and nausea ( $\mathrm{Li}$ et al., 2016), metoclopramide is the most commonly used antiemetic medication and is administered orally (Umar, 2018).

The majority of oral medications have a high solubility (Ferguson et al., 2019), but that of metoclopramide is very low $(0.986 \mathrm{mg} / \mathrm{L})$ (Kanouni et al., 2019). For this reason, we will seek in this work to develop another drug that has the same therapeutic activity of metoclopramide and a higher solubility, without influencing on the other physicochemical properties. 


\section{Problematic}

$\checkmark$ Most antiemetic drugs have a low solubility

$\checkmark$ We must develop a new drug with the same effect and higher solubility

\section{Objectives}

$\checkmark$ We will develop a drug that binds to the receptor site of metoclopramide and gives the same therapeutic activity

$\checkmark$ This medicine must have better properties (solubility) than metoclopramide

\section{Methods and Computational Details}

Using the molecular modeling and the application of the different theoretical methods we can calculate some properties: $\xi_{\mathrm{HOMO}}, \xi_{\mathrm{LUMO}},($ Santos et al., 2019) the Dipole Moment (Lindic et al., 2019), Log (P) (Caron et al., 2018), the solubility... of three bioactive molecules.

In this work we will study the affinity of molecules (Lan et al., 2019) to the receptor sites to confirm that all molecules are attached to the same receptor site (Zeng and Gifford, 2019), a comparative study of the bonds between each molecule with the receptor site helps us to know the molecule that has a great affinity so a better effect (Aviñó et al., 2019).

Then we will calculate the energies $\xi_{\text {HOMO }}$ and $\xi_{\text {LUMO }}$, the electronic chemical potential, the global hardness (Arab et al., 2016) and electrophilicity index for each molecule, in order to explain that the three molecules can belong to the same therapeutic class so they can have the same therapeutic effect (Qian et al., 2019).

In this work the chosen method is the DFT (Chanana et al., 2019) because it is the best in the electronic description of the molecule and associated properties, as well as it is widespread for the analysis of molecules for the purpose to obtain information on their structures and chemical environments. Calculations were made with TmoleX and COSMOtherm programs (Klamt and Eckert, 2004).

\section{Results and Discussion}

The two proposed molecules have a structure similar to that of metoclopramide, the only difference being the substitution of the atom "Cl" with " $\mathrm{F}$ " in the molecule_1 and the "OH" in the molecule_2, the structures of metoclopramide. and both molecules are shown in Fig. 1 to 3.

When applying the Structure/Activity relationship (Ghawanmeh et al., 2020) to these molecules, we can assume that the three molecules have the same therapeutic effect (Thirumaran et al., 2019).

To validate this proposition, we will calculate the affinity of these three molecules to the different proteins (receptor sites).

The receptor sites are: $\checkmark$ GPCR ligand: $\mathrm{G}$ protein-coupled receptors, also includes Dopamine D3 (So et al., 2020)

$\checkmark \quad$ Ion channel modulator: Ion channel modulator, is a type of drug that can modulates ion channels (Churchill et al., 2019)

$\checkmark$ Kinase inhibitor: Represent a type of enzyme inhibitor that can block the action of a protein kinases. Protein kinases are enzymes that add a Phosphate $\left(\mathrm{PO}_{4}\right)$ group to a protein and can modulate its function (Xie et al., 2020)

$\checkmark \quad$ Nuclear receptor ligands: Are active proteins in the nucleus of cells (Guan et al., 2019)

$\checkmark$ Enzyme inhibitor: Is a substance that binds to an enzyme to decrease its activity

$\checkmark$ Protease inhibitors: Are a class of antiviral drugs used in the treatment of HIV (Zhang et al., 2019b)

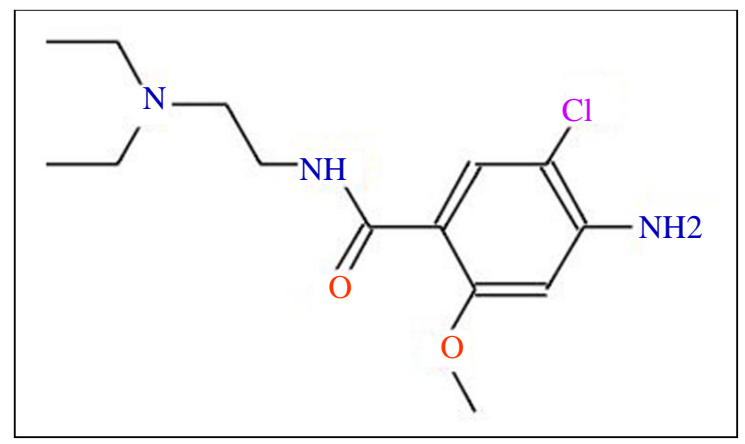

Fig. 1: The chemical structure of metoclopramide

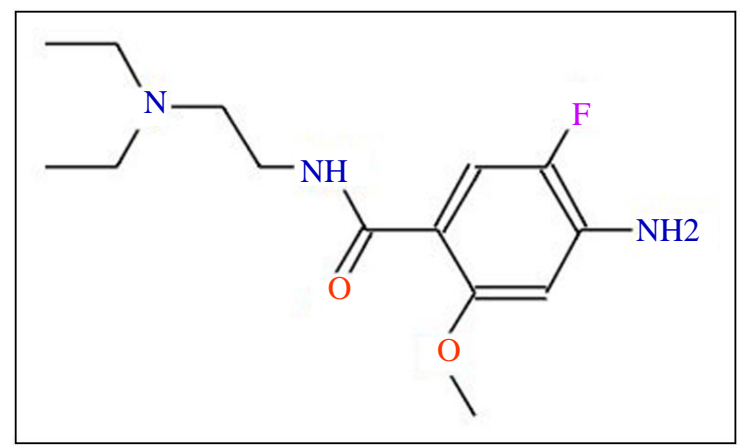

Fig. 2: The chemical structure of molécule_1

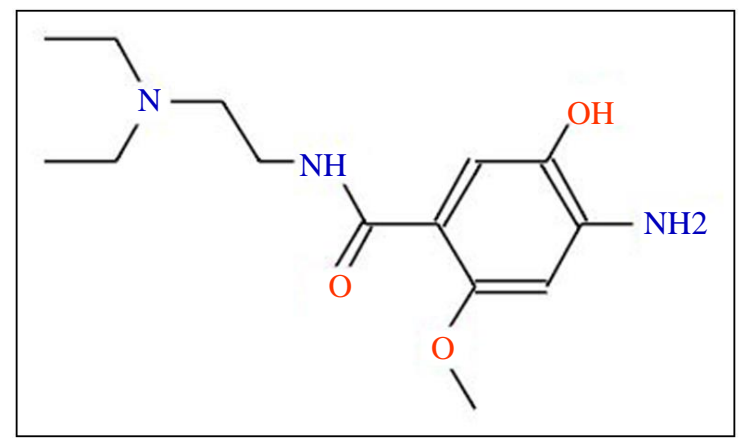

Fig. 3: The chemical structure of molécule_2 
From the affinity values towards the 6 protein receptors represented in Fig. 4 we remark that the fixation of the two molecules is directed towards the GPCR protein ligand: The G-protein coupled receptors, also includes Dopamine D3 like metoclopramide (Gurevich et al., 2016).

The most important remark in Fig. 5 is the equality of the number of rotatable bonds because there is no big difference between the three structures and also the most necessary remark is that the number of HBA and HBD of molecule_2 are greater than those of metoclopramide and molecule_1, this difference is due to the presence of the (OH) group (Palomba et al., 2018), this difference also improves the affinity of the molecule towards the receptor site.

Frontier orbitals are two types of particular molecular orbitals: the HOMO: Energy of the highest occupied molecular orbital by at least one electron and the LUMO: Energy of the lowest unoccupied molecular orbital by an electron (Zhao et al., 2019).

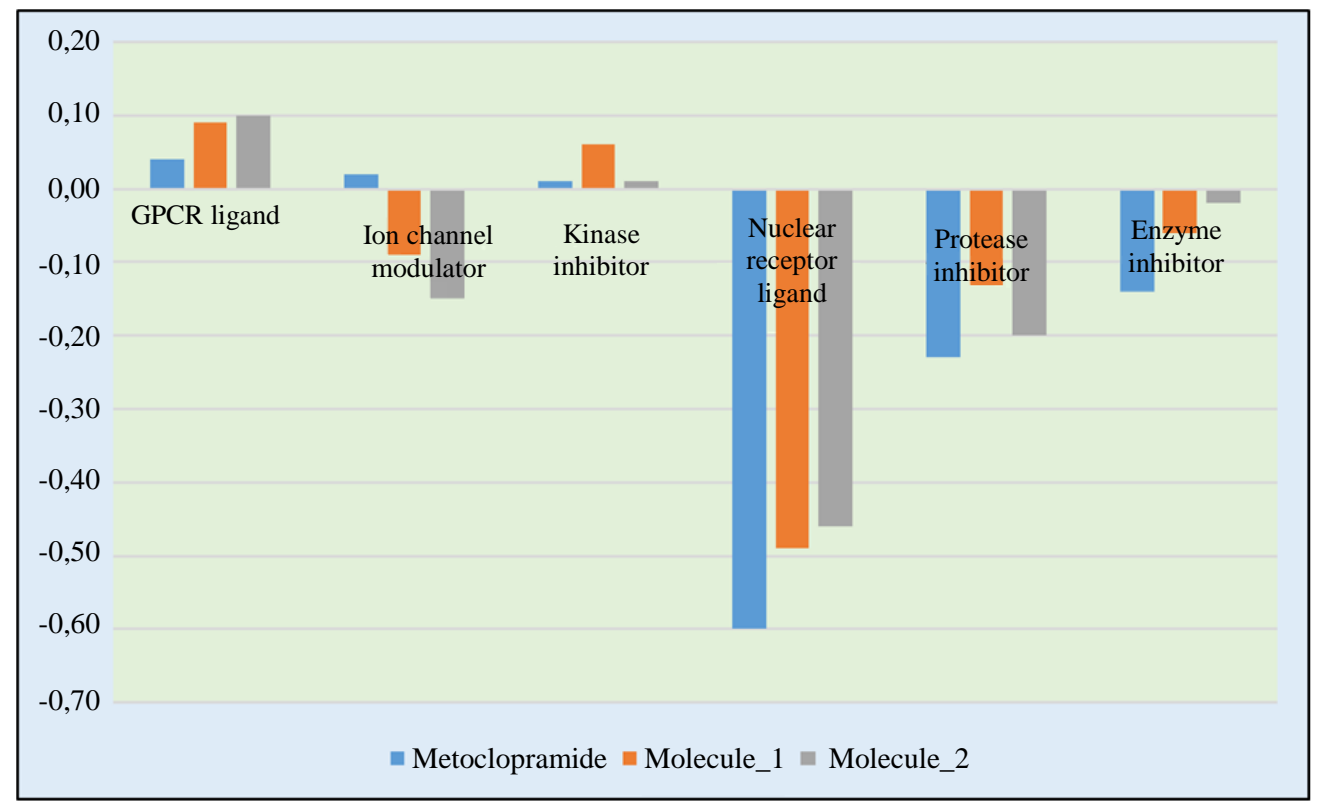

Fig. 4: Affinity of the molecules for the different receptor sites

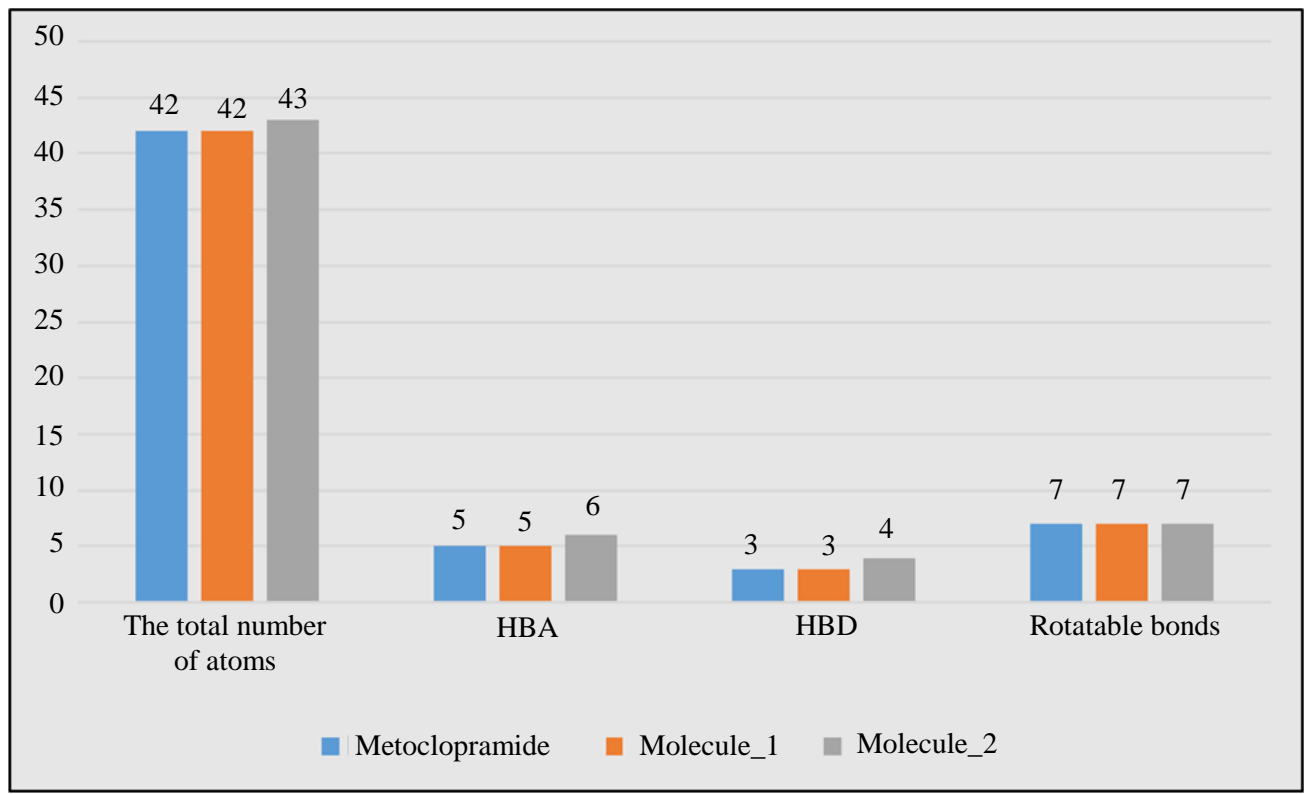

Fig. 5: Bonds made by molecules 
It has been observed in Fig. 6 that the three molecules have very close values for $\xi_{\text {номо and also }}$ for $\xi_{\text {LUMO }}$ so they have a very close reactivity, that expresses the proximity of the pharmacological effect (Mary et al., 2015) of these molecules towards the receptor site.

The electronic chemical potential $\mu$ and the global hardness $\eta$ (Zohdy et al., 2019) can be calculated from the energies of the molecular orbitals boundaries $\xi_{\text {номо }}$ et $\xi_{\text {LUMо }}$ as following:

$\mu=\left(\xi_{\text {Номо }}+\xi_{\text {LUмо }}\right) / 2$

$\eta=\left(\xi_{\text {LUMO }}-\xi_{\text {Номо }}\right)$

The electrophilicity index is defined as the energy stabilization due to the charge transfer it is noted $\omega$ (Wei et al., 2019):

$$
\omega=\mu^{2} / 2 \eta
$$

From the values of electronic chemical potential $\mu$, represented in Fig. 7 it is noted that they are almost similar (approximately $-0.12 \mathrm{au}$ ). The same remark is also observed for the electrophilicity index $\omega$ (about $0.07 \mathrm{au})$.

The global hardness $\eta$ represents the strongest index to confirm the therapeutic class of a series of drugs, we note that the values of $\eta$ are very close for the 3 molecules for that we can confirm that they belong to the same therapeutic class (Noureddine et al., 2019).

The results given in Table. 1 show that the values of the HOMO-LUMO energies are very close between the three molecules (about $3 \mathrm{eV}$ ), the same remark is also observed for the Molecular Weight (MW), the volume and the Total Polar Area Surface (TPSA), as well as the $\log (\mathrm{P})$ which makes it possible to apprehend the hydrophilic or lipophilic character of the molecule (Zhang and Jiao, 2019) and since the three molecules have a $\log (\mathrm{P})$ between $(0<\log (\mathrm{P})$ $<+5)$ we can say that they have both hydrophilic and lipophilic characters (Finat, 2016).

According to the solubility values of the two molecules represented in Fig. 8 we note that they are higher than that of metoclopramide in terms of solubility, so they will be more soluble in the blood (Loonen et al., 2019).

Table 1: Different properties of the three molecules

\begin{tabular}{llllll}
\hline $\log (\mathrm{P})$ & TPSA $\left(\mathrm{A}^{2}\right)$ & Volume $\left(\mathrm{A}^{3}\right)$ & MW $(\mathrm{g} / \mathrm{moL})$ & HOMO-LUMO $(\mathrm{eV})$ & Molecule \\
\hline 2,54 & 67,59 & 278,91 & 299,80 & 2,98 & Métoclopramide \\
2,02 & 67,59 & 270,31 & 283,35 & 2,82 & Molecule_1 \\
2 & 88 & 273 & 281 & 3,18 & Molecule_2 \\
\hline
\end{tabular}

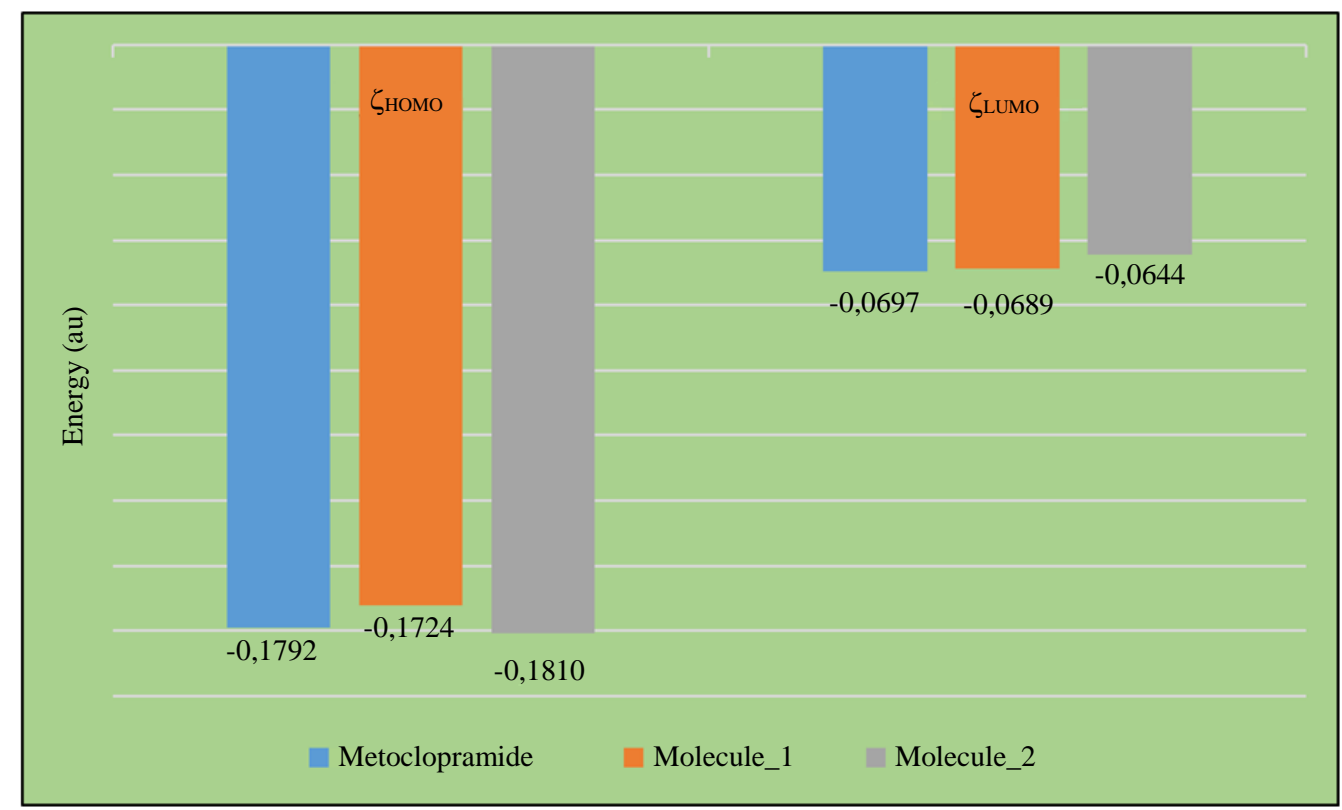

Fig. 6: Molecular orbital energies: HOMO_LUMO 


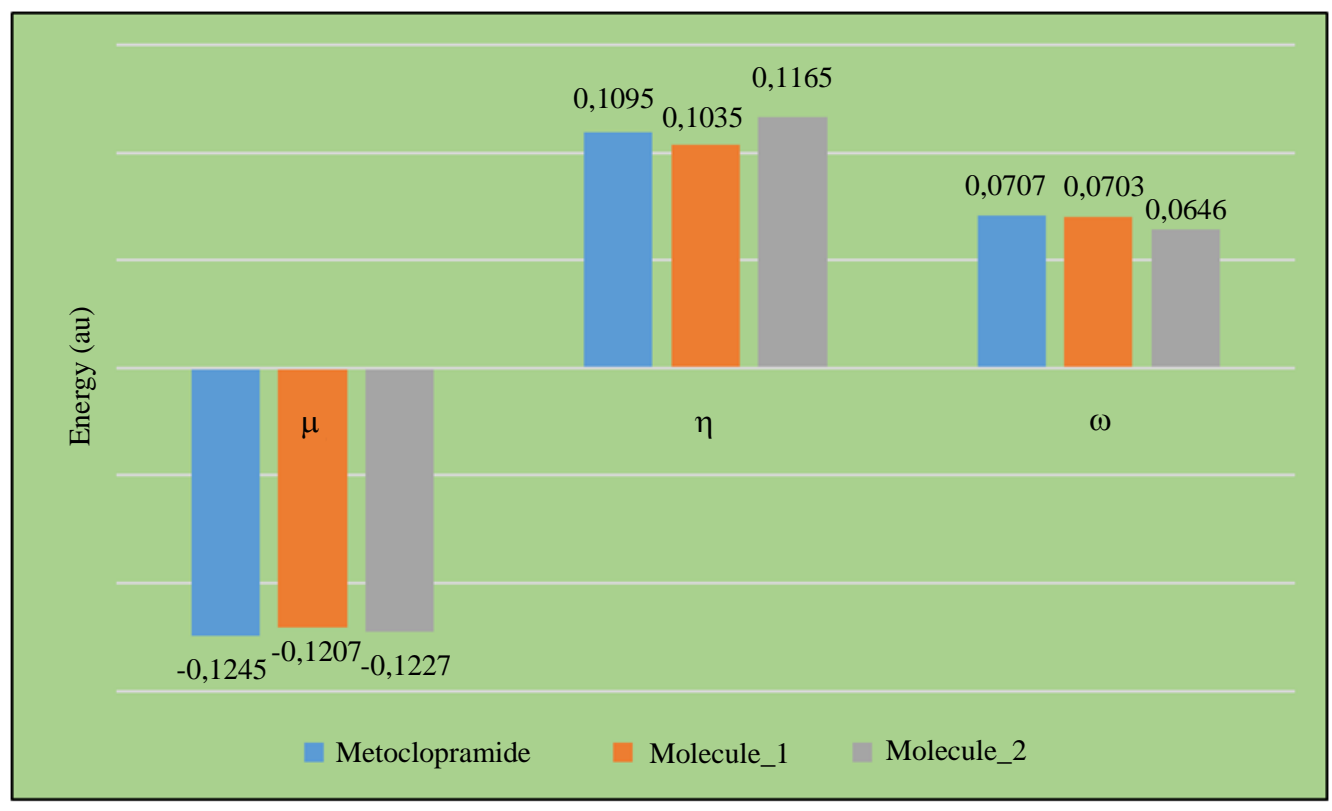

Fig. 7: The electronic chemical potential, global hardness and electrophilicity index

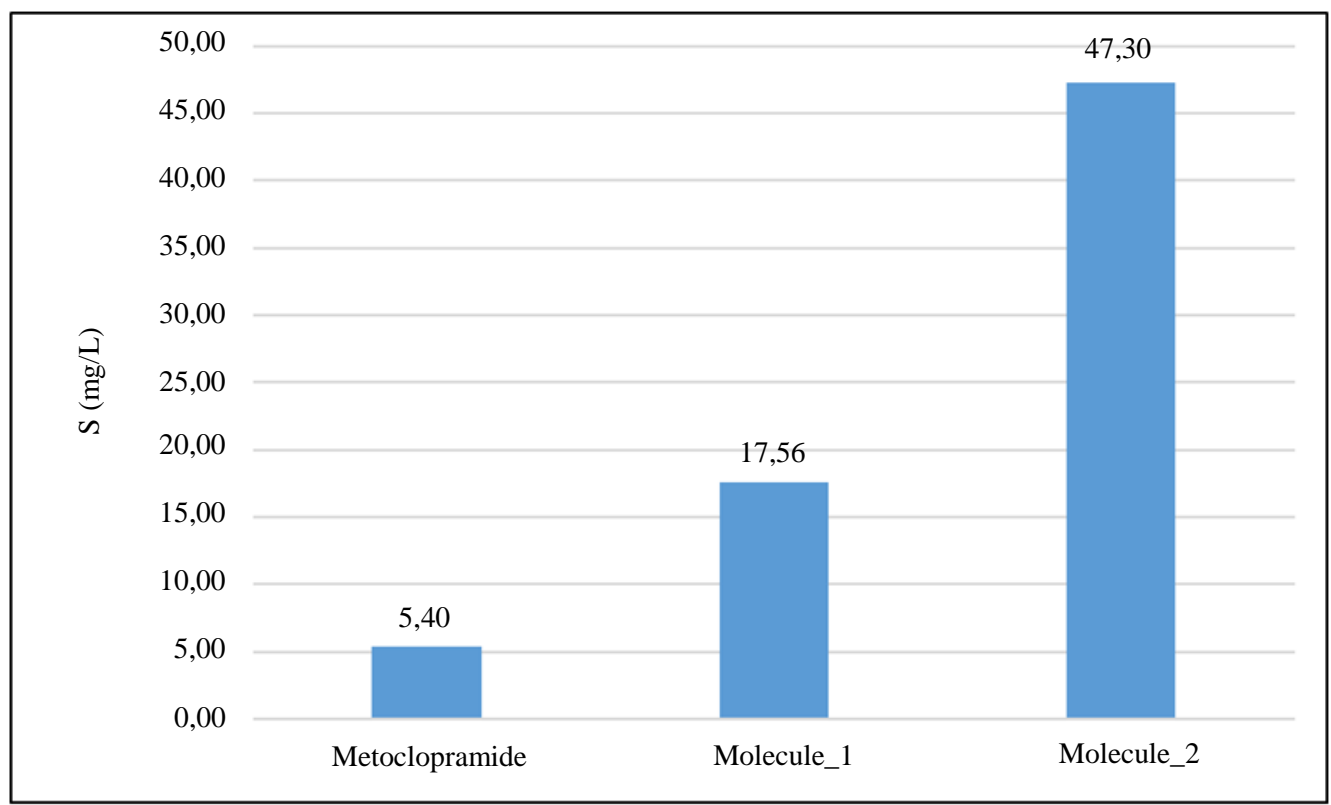

Fig. 8: Solubility values

\section{Conclusion}

Using the molecular modeling we have built two molecules whose structure is close to that of metoclopramide having similar therapeutic effect because they are fixed on the same receptor site, these molecules have a great solubility:

$\mathrm{S}$ (molecule_1) $=3 \times \mathrm{S}$ (metoclopramide)

$\checkmark \mathrm{S}$ (molecule_2) $=8 \times \mathrm{S}$ (metoclopramide)
So they have no problems of dissolution (Dong and Yang, 2020).

For the other physico-chemical properties there is a great similarity between the molecules. Thus, it can be concluded that the two proposed molecules may have antiemetic activity and the molecule_2 is the best because it has a higher solubility and also the number of HBD and HBA (Salehi et al., 2019).

This work is carried out by molecular modeling software and it will soon require in-vitro and in-vivo experiments for the confirmation of the results. 


\section{Acknowledgement}

We acknowledge the role played by Dr. KHEMILI-TALBI Souad of Université M'Hamed Bougarade Boumerdès, Algeria.

\section{Author's Contributions}

Khalil Errahmane Kanouni participated in:

$\checkmark$ Contribution and design of data

$\checkmark \quad$ Analysis and interpretation of results

$\checkmark$ Drafting the article

$\checkmark$ Read and approved the manuscript.

Yacine Benguerba participated in:

$\checkmark$ Contribution and design of data

$\checkmark$ Analysis and interpretation of results

$\checkmark$ Reviewing the article

$\checkmark$ Read and approved the manuscript.

\section{Ethics}

This article is original and contains unpublished material. The corresponding author confirms that all of the other authors have read and approved the manuscript and no ethical issues involved.

\section{References}

Arab, A., F. Ziari and M. Fazli, 2016. Electronic structure and reactivity of $\left(\mathrm{TiO}_{2}\right) \mathrm{n}(\mathrm{n}=1-10)$ nanoclusters: Global and local hardness based DFT study. Comput. Mater. Sci., 117: 90-97.

DOI: 10.1016/J.COMMATSCI.2016.01.031

Aviñó, A., A.F. Jorge, C.S. Huertas, T.F.G.G. Cova and A. Pais et al., 2019. Aptamer-peptide conjugates as a new strategy to modulate human $\alpha$-thrombin binding affinity. Biochim. Biophys. Acta BBA-Gen. Subj., 1863: 1619-1630.

DOI: 10.1016/J.BBAGEN.2019.06.014

Barabaś, A., K. Jagiełło, A. Rybińska-Fryca, A.M. Dąbrowska and T. Puzyn, 2019. How the configurational changes influence on molecular characteristics. The alkyl 3-azido-2,3-dideoxy-Dhexopyranosides-Theoretical approach. Carbohydr. Res., 481: 72-79.

DOI: 10.1016/J.CARRES.2019.06.012

Baran, Ł., 2019. Influence of the molecular geometry on the formation of the self-assembled structures. $J$. Mol. Liq., 294: 111627-111627.

DOI: 10.1016/J.MOLLIQ.2019.111627
Bošnjaković-Pavlović, N., X. Xu, D. Krstić, J.M. Gillet and Y. Wei et al., 2019. Experimental and theoretical insights of functionalized hexavanadates on $\mathrm{Na}+\mathrm{K}+-\mathrm{ATPase}$ activity; molecular interaction field, ab initio calculations and in vitro assays. J. Inorg. Biochem., 198: 110720-110720.

DOI: 10.1016/J.JINORGBIO.2019.110720

Caron, G., M. Vallaro and G. Ermondi, 2018. Log P as a tool in intramolecular hydrogen bond considerations. Drug Discov. Today Technol. Physicochem. Characterisat. Drug Dis., 27: 65-70. DOI: 10.1016/J.DDTEC.2018.03.001

Chanana, G., K. Batra and V. Prasad, 2019. Exploring response of Li2 molecule to external electric field: A DFT and SAC-CI study. Comput. Theor. Chem., 1169: 112620-112620.

DOI: 10.1016/J.COMPTC.2019.112620

Churchill, C.D.M., P. Winter, J.A. Tuszynski and M. Levin, 2019. EDEn-Electroceutical design environment: Ion channel tissue expression database with small molecule modulators. iScience, 11: 42-56.

DOI: 10.1016/J.ISCI.2018.12.003

Cui, Y., 2011. Using molecular simulations to probe pharmaceutical materials. J. Pharm. Sci., 100: 2000-2019. DOI: 10.1002/JPS.22392

Dong, J. and Z. Yang, 2020. Characterization of a new hemihydrate rebaudioside B crystal having lower aqueous solubility. Food Chem., 304: 125444-125444. DOI: 10.1016/J.FOODCHEM.2019.125444

Ferguson, C.A., W.M. Thomson, M.B. Smith, N. Kerse and K. Peri et al., 2019. Medication taking in a national sample of dependent older people. Res. Soc. Adm. Pharm.

Finat, E., 2016. A distribution formula for Kashio's padic log-gamma function. J. Number Theory, 162: 463-482. DOI: 10.1016/J.JNT.2015.11.001

Ghawanmeh, A.A., H.M. Al-Bajalan, M.M. Mackeen, F.Q. Alali and K.F. Chong, 2020. Recent developments on (-)-colchicine derivatives: Synthesis and structure-activity relationship. Eur. J. Med. Chem., 185: 111788-111788.

DOI: 10.1016/J.EJMECH.2019.111788

Guan, J., W. Zhou, M. Hafner, R.A. Blake and C. Chalouni et al., 2019. Therapeutic ligands antagonize estrogen receptor function by impairing its mobility. Cell, 178: 949-963.

DOI: 10.1016/J.CELL.2019.06.026

Gurevich, E.V., R.R. Gainetdinov and V.V. Gurevich, 2016. G protein-coupled receptor kinases as regulators of dopamine receptor functions. Pharmacol. Res., 111: 1-16. DOI: $10.1016 /$ J.PHRS.2016.05.010 
Jolfaei, N.A., N.A. Jolfaei, M. Hekmatifar, A. Piranfar and D. Toghraie et al., 2020. Investigation of thermal properties of DNA structure with precise atomic arrangement via equilibrium and non-equilibrium molecular dynamics approaches. Comput. Methods Programs Biomed., 185: 105169-105169.

DOI: 10.1016/J.CMPB.2019.105169

Kanouni, K.E., Y. Benguerba and A. Erto, 2019. Theoretical investigation of the solubility of some antiemetic drugs. J. Mol. Liq., 282: 626-632. DOI: 10.1016/J.MOLLIQ.2019.03.028

Klamt, A. and F. Eckert, 2004. Prediction of vapor liquid equilibria using COSMOtherm. Fluid Phase Equilibria, 217: 53-57. DOI: 10.1016/J.FLUID.2003.08.018

Lan, N.T., K.B. Vu, M.K. Dao Ngoc, P.T. Tran and D.M. Hiep et al., 2019. Prediction of AChE-ligand affinity using the umbrella sampling simulation. J. Mol. Graph. Model., 93: 107441-107441.

DOI: 10.1016/J.JMGM.2019.107441

Lecerf, M., A. Kanyavuz, S. Lacroix-Desmazes and J.D. Dimitrov, 2019. Sequence features of variable region determining physicochemical properties and polyreactivity of therapeutic antibodies. Mol. Immunol., 112: 338-346.

DOI: 10.1016/J.MOLIMM.2019.06.012

Lewars, E., 2019. Chapter 7-Personal Computers in Computational Chemistry. In: Mathematical Physics in Theoretical Chemistry, Developments in Physical and Theoretical Chemistry, Blinder, S.M. and J.E. House (Eds.), Elsevier, pp: 219-260.

Li, Y.X., Y.L. Jiang, Y.P. Yi, W.L. Liu and Y.X. Tang et al., 2016. Application of auricular acupoints therapy in relieving the gastrointestinal side effects induced by chemotherapy: An integrative review. Chin. Nurs. Res., 3: 58-61.

DOI: 10.1016/J.CNRE.2016.06.004

Lindic, M.M., M. Zajonz, C. Gers-Panther, T.J.J. Müller and M. Schmitt, 2019. The excited state dipole moment of 2-[(4-methoxyphenyl)ethynyl]-3-(1methyl-1H-indol-3-yl)-quinoxaline from thermochromic shifts. Spectrochim. Acta. A. Mol. Biomol. Spectrosc.

Loonen, A.J.M., S. Leijtens, O. Serin, M. Hilbink and P.C. Wever et al., 2019. Soluble mannose receptor levels in blood correlate to disease severity in patients with community-acquired pneumonia. Immunol. Lett., 206: 28-32. DOI: 10.1016/J.IMLET.2018.12.001

Mary, Y.S., H.T. Varghese, C.Y. Panicker, T. Thiemann and A.A. Al-Saadi et al., 2015. Molecular conformational analysis, vibrational spectra, NBO, NLO, HOMO-LUMO and molecular docking studies of ethyl 3-(E)-(anthracen-9-yl)prop-2-enoate based on density functional theory calculations. Spectrochim. Acta. A. Mol. Biomol. Spectrosc, 150: 533-542. DOI: 10.1016/J.SAA.2015.05.092
Noureddine, O., S. Gatfaoui, S.A. Brandán, H. Marouani and N. Issaoui, 2019. Structural, docking and spectroscopic studies of a new piperazine derivative, 1-Phenylpiperazine-1,4-diium bis(hydrogen sulfate). J. Mol. Struct.

Palomba, T., G. Ciancaleoni, T. Del Giacco, R. Germani and F. Ianni et al., 2018. Deep eutectic solvents formed by chiral components as chiral reaction media and studies of their structural properties. J. Mol. Liq., 262: 285-294. DOI: 10.1016/J.MOLLIQ.2018.04.096

Qian, J., C. Zhao, J. Tong, S. Jiang and Z. Zhang et al., 2019. Study the effect of trypsin enzyme activity on the screening of applying frontal affinity chromatography. Int. J. Biol. Macromol., 139: 740-751. DOI: 10.1016/J.IJBIOMAC.2019.07.218

Rasmussen, K., H. Rauscher, A. Mech, J. Riego Sintes and D. Gilliland et al., 2018. Physico-chemical properties of manufactured nanomaterials-Characterisation and relevant methods. An outlook based on the OECD Testing Programme. Regul. Toxicol. Pharmacol., 92: 8-28. DOI: 10.1016/J.YRTPH.2017.10.019

Salehi, H.S., M. Ramdin, O.A. Moultos and T.J.H. Vlugt, 2019. Computing solubility parameters of deep eutectic solvents from molecular dynamics simulations. Fluid Phase Equilibria, 497: 10-18. DOI: 10.1016/J.FLUID.2019.05.022

Santos, E.S., V.S. Reis, L. Guimarães and C.S. Nascimento, 2019. Molecular wires formed from native and push-pull derivatives polypyrroles and $\beta$ cyclodextrins: A HOMO-LUMO gap theoretical investigation. Chem. Phys. Lett., 730: 141-146. DOI: 10.1016/J.CPLETT.2019.05.058

So, S.S., T. Ngo, P. Keov, N.J. Smith and I. Kufareva, 2020. Chapter 16-Tackling the complexities of orphan GPCR ligand discovery with rationally assisted approaches. Struc. Funct. Drug Dis.

Stellmach, J.A., 2009. The influences of the structure and activity of biologically active compounds on the assessment of inventive step. World Pat. Inf., 31: 226-234. DOI: 10.1016/J.WPI.2008.12.001

Thirumaran, S.L., A. Lepailleur and C. Rochais, 2019. Structure-activity relationships of serotonin 5-HT7 receptors ligands: A review. Eur. J. Med. Chem., 183: 111705-111705.

DOI: 10.1016/J.EJMECH.2019.111705

Umar, R.M., 2018. Drug-drug interactions between antiemetics used in cancer patients. J. Oncol. Sci., 4: 142-146. DOI: 10.1016/J.JONS.2018.07.003

Wei, Z., W. Li, D. Zhao, Y. Seo and R. Spinney et al., 2019. Electrophilicity index as a critical indicator for the biodegradation of the pharmaceuticals in aerobic activated sludge processes. Water Res., 160: 10-17. DOI: 10.1016/J.WATRES.2019.05.057 
Wormald, J.L. and A.I. Hawari, 2017. Generation of phonon density of states and thermal scattering law using ab initio molecular dynamics. Prog. Nucl. Energy, 101: 461-467.

DOI: 10.1016/J.PNUCENE.2017.02.011

Xie, Y., J. Ding, X. Cui, M. Wu and C. Huang et al., 2020. Screening of kinase inhibitors downregulating PD-L1 expression via on/in cell quantitative immunoblots. Eur. J. Pharm. Sci., 142: 105088-105088.

DOI: 10.1016/J.EJPS.2019.105088

Zeng, H. and D.K. Gifford, 2019. Quantification of uncertainty in Peptide-MHC binding prediction improves high-affinity peptide selection for therapeutic design. Cell Syst., 9: 159-166.

DOI: 10.1016/J.CELS.2019.05.004

Zeng, X., T. Han, Y. Guo and F. Wang, 2018. Molecular dynamics modeling of crack propagation in titanium alloys by using an experiment-based Monte Carlo model. Eng. Fract. Mech., 190: 120-133.

DOI: 10.1016/J.ENGFRACMECH.2017.12.012

Zhang, S. and Y. Jiao, 2019. Effects of hydrophilic/lipophilic nanoparticles on the decomposition of $\mathrm{NH}_{4} \mathrm{HCO}_{3}$ solution. Chem. Phys. Lett., 719: 54-58.

DOI: 10.1016/J.CPLETT.2019.02.002
Zhang, B., X. Hou, L. Dang and H. Wei, 2019a. Selective polymorphic crystal growth on selfassembled monolayer using molecular modeling as an assistant method. J. Cryst. Growth, 518: 81-88. DOI: 10.1016/J.JCRYSGRO.2019.04.031

Zhang, X., K. Guo, Z. Dong, Z. Chen and H. Zhu et al., 2019b. Kunitz-type protease inhibitor BmSPI51 plays an antifungal role in the silkworm cocoon. Insect Biochem. Mol. Biol.

Zhao, X., C. Chen, Q. Sun, Y. Li and H. Yu, 2019. Molecular structure optimization design of inhibitors based on frontier orbitals theory. Applied Surf. Sci., 494: 895-907. DOI: 10.1016/J.APSUSC.2019.07.248

Zhu, Y., X. Xu, X. Zhang, Y. He and X. Zeng et al., 2018. Computational screening and molecular design of anthracene-based semiconductors. Org. Electron, 61: 87-95. DOI: 10.1016/J.ORGEL.2018.06.041

Zohdy, K.M., A.M. El-Shamy, A. Kalmouch and E.A.M. $\mathrm{Gad}, 2019$. The corrosion inhibition of $\left(2 \mathrm{Z}, 2^{\prime} \mathrm{Z}\right)$ 4,4'-(1,2-phenylene bis(azanediyl))bis(4-oxobut-2enoic acid) for carbon steel in acidic media using DFT. Egypt. J. Pet., 28: 355-359.

DOI: 10.1016/J.EJPE.2019.07.001 